\title{
O impacto das certificações nas cadeias globais de valor agrícolas: o caso das frutas frescas no Nordeste brasileiro
}

\author{
Thales Augusto Medeiros Penha \\ Universidade Federal do Rio Grande do Norte - Natal - Rio Grande do Norte - \\ Brasil \\ Walter Belik \\ Universidade Federal do Rio Grande do Norte - Natal - Rio Grande do Norte - \\ Brasil
}

\section{Resumo}

O objetivo do trabalho é investigar o papel das certificações na coordenação das cadeias globais de frutas frescas, ressaltando mais especificamente o caso das frutas tropicais produzidas nos Polos irrigados de Petrolina-Juazeiro e Açú-Mossoró localizados na região Nordeste do Brasil. Observa-se nas últimas décadas uma crescente relevância da atuação dos selos de certificações nas cadeias de produtos frescos. Este movimento é encabeçado por cadeias de supermercados que estabeleceram procedimentos a serem adotados dentro dos integrantes das cadeias globais de produtos frescos. Portanto, este trabalho parte das seguintes questões de pesquisa: qual tem sido o papel desempenhado pelas certificações nas cadeias globais de frutas frescas produzidas no Nordeste? Para responder tais questões este trabalho se apoia na literatura identificando autores com a temática da Economia da Qualidade, em especial na certificação, com seus impactos na coordenação das cadeias globais de frutas frescas. Além disso, foram coletados dados secundários de bases estatísticas, bem como, foi realizada uma pesquisa de campo. Observou-se que as certificações desempenham um papel central na cadeia de produção de frutas frescas da região, uma vez que define os padrões técnicos e normas éticas de produção, bem como, consegue se apropriar das quase-rendas geradas dentro da cadeia.

Palavras-chaves: Certificações. Sistema agroalimentar. Fruticultura. Cadeias globais de valor.

The impact of quality certifications in the global agricultural value chain: the case of fresh fruits in Brazilian Northeast

\footnotetext{
Abstract

The aim of this paper is to investigate the role of certifications in the coordination of the global chains of fresh fruits, highlighting more specifically the case of tropical fruits produced in the Petrolina-Juazeiro and Açú-Mossoró irrigated areas located in the Northeast region of Brazil. Over the past few decades, there has been a growing relevance of the performance
} 
of certification stamps in fresh produce chains. This movement is introduced by supermarket chains that have established procedures to be adopted within the agents inside of the global chains of fresh produce. Therefore, this work is based on the following research questions: what has been the role played by certifications in the global chains of fresh fruits produced in the Northeast? To answer such questions, this paper works on Economics of Quality, specially on certifications and their impacts on the coordination of global fresh fruit chains. In addition, secondary data were collected from statistical bases, as well as, a field survey was performed. It was noted that certifications play a central role in the chain of fresh fruit production in the Northeast since it defines the technical standards and ethical standards of production, as well as, it can appropriate the quasi-rents generated within the chain.

Key-words: Certification. Agrifood system. Fresh fruit sector. Global value chain.

\section{El impacto de las certificaciones en las cadenas globales de valor agrícola: el caso de las frutas frescas en el Nordeste brasileño}

\section{Resumen}

El objetivo del trabajo es investigar el papel de las certificaciones en la coordinación de las cadenas globales de frutas frescas, resaltando más específicamente el caso de las frutas tropicales producidas en los Polos irrigados de Petrolina-Juazeiro y Açú-Mossoró ubicados en la región Nordeste de Brasil. Se observa en las últimas décadas una creciente relevancia de la actuación de los sellos de certificaciones en las cadenas de productos frescos. Este movimiento es encabezado por cadenas de supermercados que establecieron procedimientos a ser adoptados dentro de los integrantes de las cadenas globales de productos frescos. Por lo tanto, este trabajo parte de las siguientes cuestiones de investigación: cuál ha sido el papel desempeñado por las certificaciones en las cadenas globales de frutas frescas producidas en el Nordeste? Para responder estas cuestiones este trabajo analiza la contribución de la Economía de la Calidad, especialmente el tema de las certificaciones y sus impactos en la coordinación de las cadenas globales de frutas frescas. Además, se recogieron datos secundarios de bases estadísticas, así como, se realizó una investigación de campo. Se observó que las certificaciones desempeñan un papel central en la cadena de producción de frutas frescas del noreste, ya que define los patrones técnicos y normas éticas de producción, así como, se apropia de las cuasi rentas generadas dentro de la cadena.

Palabras clave: Certificaciones. Sistema agroalimentario. El cultivo de frutas. Cadenas globales de valor.

\section{Introdução}

A produção, distribuição e comercialização de produtos agroalimentares apresentaram uma profunda reestruturação nas últimas décadas, como aponta Bursch et al. (2005). Este fato tem instigado um debate efervescente sobre o futuro do sistema agroalimentar mundial. No entanto, qualquer discussão sobre o futuro do sistema alimentar deve ter em seu cerne uma compreensão sobre os elementos que normalmente associam a dinâmica dos mercados alimentares à dinâmica da produção agrícola.

Desta forma, para dar conta de uma abordagem atualizada do presente sistema agroalimentar é preciso analisar três elementos constitutivos fundamentais e como estes se interrelacionam, são eles: a cadeia de valor dos alimentos, os ambientes alimentares (contexto físico e cultural) e o comportamento do consumidor (HLPE 2017). 
Em relação à cadeia de valor dos produtos agroalimentares é interessante notar uma contradição importante. No chamado regime de variedade (Coriat, 1997), com seus mercados diferenciados, o ato de processar o alimento diminui o seu valor adicionado. Contrariando o senso comum, produtos "mais naturais" necessitam de mais tecnologia. Ademais, o padrão "distance and durability" (Friedman, 1992) demanda maiores investimentos em distribuição - atraindo empresas do setor de logística e comercialização. A distância física é cada vez menos uma barreira à comercialização. Analisar o Ambiente alimentar, por sua vez. significa entender o que o produto agroalimentar representa para a sociedade. Mais do que um bem voltado para a nutrição, esses produtos assumem funções no campo simbólico que podem ser consideradas são pontes para novos mercados (Roberts, 2008). Por fim com relação ao comportamento do consumidor este passou dar maior importância a aspectos que vinculam os produtos a práticas sustentáveis, do ponto de vista ecológico, e saudáveis, em relação a aspectos nutricionais (Funcke et al, 2009).

Diante disso observa-se a presença de um novo regime baseado na variedade, mas não é o fim da produção em massa embora haja uma relevância cada vez maior dos aspectos ligados à qualidade do produto (Coriat, 1997). Segundo Coriat (1997) trata-se de um regime de variedade como uma variante pós fordista. Nesse caso, as "convenções de qualidade" passam a ter uma grande importância, embora não haja legislação estabelecida em termos globais'.

As convenções de qualidade, portanto, passam a ser o ponto central de governança das cadeias agrícolas globais, uma vez que é o atributo específico desejado pelos consumidores. Sendo assim a coordenação de toda cadeia estruturase de modo a assegurar a presença da especificidade desejada bem como define quem irá se apropriar do valor adicional herdado por este atributo. Diante disso emergem as certificações e selos criados por redes varejistas e atacadistas na busca de uma coordenação estrita ao longo da cadeia de valor agroalimentar. Isto posto, este trabalho parte do seguinte problema de pesquisa: qual o impacto das certificações na governança das cadeias globais de valor dos produtos agroalimentares?

Tendo vista que a governança das cadeias de valor é específica dada à relação entre os agentes envolvidos, assim como, o tipo de produto, como aponta Gereffi; Humphrey \& Sturgeon (2005). É incoerente definir uma forma geral de como as certificações repercutem nas cadeias globais de valor. Sendo assim, este artigo define como objeto de estudo as cadeias globais de valor de frutas frescas instaladas na região Nordeste do Brasil. Tal objeto se justifica pelo fato do ramo de FLV - Frutas, Legumes e Verduras apresentar uma das maiores taxas de crescimento nas quantidades comercializadas nas últimas décadas (Penha, 2018). Nesse particular, o setor de frutas tem ganhado um maior protagonismo no varejo de produtos agroalimentares, principalmente nos supermercados, devido a sua capacidade de agregação de valor (Dolan \& Humphrey (2000).

\section{Integração das Cadeias Agroalimentares}

\footnotetext{
${ }^{1}$ Como menciona Roberts (2008:282) “Today's value added is tomorrow's commodity”, reproduzindo entrevista com um dos fundadores da Country Natural Beef, associação de criadores de gado “orgânico" dos Estados Unidos.
} 
A evolução dos mercados nas últimas décadas levou a que os produtores se inserissem monotonamente na produção de commodities com a finalidade de prover matérias primas para a indústria de alimentos, rações ou bioenergia ou, alternativamente, na produção de especialidades para o consumo in natura ou processados para consumidores de alta renda ou nichos de mercado.

Ironicamente, essas duas ramificações da produção agrícola apontam para o norte da concentração e da exclusão. Por um lado, a commoditização com o modelo de agroindustrialização leva a aumentos crescentes de escala e um distanciamento cada vez maior da natureza. Por outro lado, a produção de especialidades enseja a "acomodação higiênica da vida rural" (Marsden, 2001) com custos elevados voltados para padrões sanitários quase inalcançáveis e altos custos impostos pela regulação oficial e autoregulação que reforçam o domínio da agroindústria. Novos investimentos (ambientais, bem-estar animal, certificações etc.) levam a novos custos e o preço pago pelos produtores para a manutenção de pequenas escalas é o aperfeiçoamento constante de um modelo que possa se beneficiar de sinergias que se possa extrair seja da heterogeneidade da produção ou do consumo (Marsden, 2009).

Alguns autores trabalham o paradigma da "Distância e Durabilidade" para explicar as bases do Sistema Alimentar atual (Friedman, 1992). Considerando a produção de commoddities ou de especialidades é certo que o alcance dos mercados tende a ser global e os produtos alimentares tendem a reduzir as suas características de perecibilidade para poderem atender melhor os consumidores. No caso da distância, importa cada vez menos o tamanho do percurso a ser percorrido pelo produto e cada vez mais o tempo de ligação do campo à mesa. A respeito da durabilidade esta enseja uma visão ampliada do que podermos considerar por produtos frescos, que por sua vez passam a fazer uso de refrigeração e conservantes para garantir o acesso a um raio de consumidores cada vez maior. Por esse motivo as chamadas cadeias curtas de suprimento nem sempre estariam levando em conta a geografia, mas sim o movimento de coordenação estrita exercido pelos agentes envolvidos no processo. Na realidade, o sistema pós fordista observado na produção de alimentos se traduz por processos descentralizados e flexíveis considerando a organização da produção e a busca por economias de escala a e de escopo. A governança das cadeias produtivas de alimentos é, de modo geral, vertical embora faça uso da flexibilidade proporcionada pelas novas tecnologias para atuar em diferentes espaços geográficos de forma horizontal (Jha \& Chakraborty, 2014).

Normalmente os circuitos curtos de produção são associados ao conceito de "place embedded" estando de forma oposta ao "placeless food". No entanto, o "place embedded" tem sido visto como uma estratégia de resistência contra a globalização e o neoliberalismo. Como muitos sublinham, trata-se de uma resistência também às multinacionais e alimentos "sem origem e homogeneizados, de práticas gastronômicas padronizadas" (Goodman, 2017:64). Fala-se em um contexto pósprodutivista no qual as cadeias curtas de produção seriam uma novidade e uma primeira etapa para um processo de recampesinação (Ploeg, 2010). No entanto, muitos acreditam que o "place embeddedness" é apenas uma forma de cooptação que age de maneira similar à globalização (DuPuis; Goodman \& Hill, 2006). A onda de comidas locais e outras sofisticações seriam apenas mais um dos aspectos da terceira onda de "marketização", voltada para se apropriar de nichos (Fonte, 2010). Como 
afirma Goodman “...sem mudanças políticas e institucionais profundas, as redes alimentares alternativas correm o risco de ficar limitadas a prover "pessoas abastadas" em espaços de consumo circunscritos, cujas fronteiras são patrulhadas por varejistas rentistas ávidos de novas oportunidades para diferenciar suas linhas de produtos" (2017: 77).

A esse respeito vale registrar a crítica de Torey (2010) segundo a qual não é só a localização e as práticas de produção que caracterizariam uma rede alternativa, mas também a forma de comercialização. Segundo a autora, há uma preocupação com os movimentos que querem se posicionar nos mercados de massa e envolver consumidores em grande escala com os supermercados, que representaria um investimento em um sistema burocratizado e racionalizado e com "standards". Em outras palavras, uma coisa é avançar alternativas para o comércio "mainstream" e outra é avançar com o "mainstream" fazendo alianças com as grandes corporações do varejo.

O interessante nessa discussão é a possibilidade de "criação de mercado" a partir da identificação e reconhecimento de um atributo que está ligado à produção do produto que está sendo comercializado. Por exemplo, uma produção de frutas frescas para exportação só será bem-sucedida se houver um mercado que possa atestar a qualidade e recompensar o esforço de toda a cadeia com uma melhor remuneração. Ou seja, a apropriação de rendas diferenciais por qualquer um dos elos da cadeia produtiva só pode acontecer na medida em que se abre um mercado para esse bem. Como se extrai unidades de um recurso está na medida da diferença entre a coletivização e o controle privado desse recurso. Na realidade, o uso desse recurso por uma pessoa não exclui a possibilidade de outras pessoas fazerem uso do mesmo, mas se não houver um método claro de apropriação de unidades todo o sistema pode entrar em colapso (Ostrom, 1990). Isso se torna particularmente verdade no caso do uso da água, mas também é evidente na natureza intangível corporificada em uma fruta tropical procedente de alguma origem exótica.

No caso dos alimentos, a flexibilidade e a competitividade estabelecidas pelo sistema de produção pós fordista se concretizam por meio de serviços e logística dentre as diversas dimensões que fazem parte do composto do produto. A tecnologia de informação permite alongar a cadeia, mas, em função da necessidade de padronização, reduz-se a diversidade e as possibilidades de especialização (Baldwin, 2013). Em termos históricos, do ponto de vista da coordenação da cadeia, a ampliação do uso da informática e telecomunicações diminuiu as possibilidades de desagregação mas, ao mesmo tempo, permitiu trabalhar com mão de obra de baixa qualificação. Em resumo: o que vale para a economia industrial pode ser aplicado no sistema agroindustrial.

Já a organização da cadeia de distribuição de frutas frescas para os mercados no exterior em contraestação enseja uma forma de governança baseada em contratos. Esse sistema não só é a "escolha natural" - estabelecida pela redução dos custos de transação, conforme demonstra a teoria microeconômica baseada na Nova Economia Institucional, como também o sistema que reduz custos de produção e os chamados custos de mensuração (Barzel 1982), que são os mais relevantes para esse caso. As cadeias de produção são formadas a partir de relações técnicas, mas o formato híbrido de relação entre os elos da cadeia está relacionado à especificidade do ativo transacionado e às assimetrias de informação entre os agentes (Penha, 
2018). Por outro lado, a formação de grupos estratégicos dentro de uma cadeia explica as diferenças nos tipos de economia contratual (Farina \& Zylberstajn, 2012). Claude Menard (2013) denomina essa diversidade de formas plurais relacionamento e a explicação para a sua existência não está em questões Financeiras, tecnológicas ou de tipo de inovação utilizada (entre outras) e sim nas dificuldades que os próprios agentes possuem em identificar o grau de especificidade do ativo e monitorar as transações. Pode haver também uma explicação em relação à estratégia adotada que faz com que o produto seja distribuído por "traders" ou diretamente por supermercados.

A diversificação por parte da oferta e a busca de qualidade estão ligadas diretamente à saturação de mercados. Produtos de qualidade não obrigatória (ou qualidade relativa) são medidos por sinais de qualidade e a convenção social que define a qualidade é o resultado da coordenação entre atores e baseado em um dispositivo institucional. Esse conceito se diferencia dos "standards", que são regras objetivas. Nos EUA as convenções de qualidade são mais frouxas, pois se acredita que o consumidor pode decidir individualmente com as informações disponíveis no mercado (Sylvander, 1985). Referindo-se à "crise da vaca louca" e outras contaminações de alimentos observadas na Europa nos anos 90, Valseschini \& Nicolas (1985) chamam a atenção para o fato de que sempre ocorreram problemas sanitários e nutricionais. A diferença é que hoje - com a saturação dos mercados e com a liberalização do comércio a qualidade tornou-se uma questão mais abrangente. Considerando que a cadeia de suprimentos ficou mais longa, torna-se necessário maior esforços para que produtores e consumidores possam exercer algum controle. Em suma, a concorrência no Sistema Alimentar está levando a uma generalização de regras baseadas na qualidade e isso acaba por exigir transformações nas relações industriais e mercantis. Os governos necessitam alterar as práticas e o posicionamento da política pública e, do ponto de vista privado, o consumidor que, evidentemente, não é onisciente necessita da informação dada pela certificação.

A construção do ambiente institucional mencionado anteriormente, tem como componente primordial as regras estabelecidas pelas políticas públicas e esse conjunto de fatores influencia o formato dos arranjos institucionais na medida em que as mesmas mexem com os custos de transação e, por consequência, com a escolha de estruturas de governança e sua performance (Wiliamson, 1995; Menard, 1996). Cabe, porém uma atualização: em tempos de auto-regulação privada e estado mínimo as políticas públicas a que nos referimos estão sendo substituídas cada vez mais pela certificação privada.

Nesse particular, é importante diferenciar os "standards" (padrões) dos "grades" (Classificações). O primeiro está baseado em acordos sanitários e regulações do mercado internacional. O Codex Alimentarius - administrado pela FAO e WHO - organismos do sistema das Nações Unidas, é a fonte primária de definição de "standards" para a área de alimentos sendo utilizada como base para o comércio internacional (Farina \& Reardon, 2000). Já os "grades" representam uma classificação baseada em atributos qualitativos. Sabemos que a qualidade é uma convenção social e, portanto, o resultado alcançado na coordenação dos atores pode estar baseado em quatro elementos principais, complementares ou não, a saber: regras objetivas acordadas entre as partes, ligações duráveis entre atores, 
"coordenação cívica" (em torno de uma causa) e melhor funcionamento do mercado (Sylvander, 1995)2.

O estabelecimento de um padrão de qualidade baseado em uma certificação pode diminuir as assimetrias de informação (Akerlof, 1978) que na agricultura levam ao oportunismo do produtor ao distribuidor. Vale mencionar que o oportunismo está presente na agricultura não somente devido à racionalidade limitada, mas também, e principalmente, em função do processo biológico e do meio ambiente. Com o objetivo de minimizar esta situação os agentes investem em ativos dedicados ("sunk costs") que visam adaptar o sistema de produção às regras específicas colocadas pela certificação, embora no mundo em que o conhecimento não é distribuído de forma equilibrada não é possível que todos tenham os mesmos custos de produção (Langlois, 1998).

A certificação obedece a uma lógica determinada visando reduzir custos de transação e mensuração, pois não estamos nos referindo ao produto per si, mas sim a um conjunto de atributos. Nesse sentido a fruta fresca transacionada carrega consigo não só características organolépticas, mas também atributos culturais, sociais e ambientais que possam ser reconhecidos de imediato pelo público consumidor. A seção seguinte se aprofundará na coordenação das cadeias de frutas frescas, colocando no cerne do debate o papel das certificações.

\section{0 novo padrão dos mercados agrícolas: certificação e os mecanismos de coordenação nas cadeias de frutas frescas}

Observa-se nos últimos anos uma ampliação significativa de certificações privadas cadeias de FLV que em grande medida atuam na tentativa de ampliar a parcela de valor adicionado gerado na produção (Busch \& Bain, 2004). Considerando que esse setor específico não é dominado por trading companies, e, portanto, não possuem marcas expressivas que impactem na preferência dos consumidores os processos de produção necessitam agregar valor a partir da criação de atributos. As redes de supermercados, como exemplos mais comuns, buscam se apropriar de parcelas maiores do valor adicionado criando suas marcas próprias de alimentos (Dolan \& Humphrey, 2000).

Este modelo pós fordista, também considerado flexível porque é ativado pela demanda (Belik, 2007), é, em grande medida, adotado pelos atores mais próximos do consumidor considerando a cadeia produtiva como um todo: ou seja: redes de supermercados, grandes varejistas e atacadistas. Esse novo paradigma tem sua nova dinâmica centrada na geração de quase-rendas, a qual é obtida através de investimento em ativos específicos que permitem a diferenciação de produto (Klein et al., 1978).

\footnotetext{
${ }^{2} \mathrm{Na}$ França o sistema de Appellation d'Origene Contrôllé (AOC) foi criada por via administrativa em 1919 para os vinhos e se expandiu rapidamente para outros produtos como os queijos, manteiga, mel etc. A AOC está baseada em atributos geográficos objetivos, mas a subjetividade do consumidor em relação aos sinais de qualidade estabelece as preferências e os hábitos de compra. Mais tarde, a partir dos anos 1960 criaram-se outros tipos de Standards, não ligados diretamente à geografia, mas à uma convenção de qualidade específica estabelecida pelos próprios fabricantes e administrada de forma privada. Esse é o caso do "label rouge" utilizado para carnes, produtos da "montanha" ou produtos da "fazenda".
} 
Entretanto, é importante ressaltar a relação de poder assimétrica na cadeia devido à estrutura oligopsônica deste mercado, uma vez que algumas poucas redes de supermercado concentram as vendas aos consumidores finais, como mostram os trabalhos de Gwynne (1999) e da Oxfam (2014). Deste modo, como o mercado está organizado com a oferta de um grande número de produtores globais vendendo para uma quantidade reduzida de atacadistas e varejistas faz com que esses últimos tenham maior poder dentro da relação.

Assim, verifica-se uma estrutura de governança do tipo relacional (Gereffi; Humphrey \& Sturgeon, 2005) no sentido de que, uma vez que o produto ofertado pelos produtores carrega alto grau de especificidade e necessita de fortes esforços de apropriação de competências, os agentes envolvidos nos elos à jusante da cadeia não conseguem hierarquizar o processo. Todavia, como as especificações produtivas estão sob controle dos compradores que exigem determinados atributos - e que, inclusive, modificam-se ao longo do tempo, exige-se uma forte coordenação e interação entre estes compradores e produtores com um claro grau de domínio dos compradores sobre os vendedores quanto à capacidade de apropriação do valor adicionado.

Diante disso, alguns autores têm se debruçado sobre as práticas de criação ou reconhecimento da qualidade por parte dos agentes da cadeia produtiva de alimentos, vertente de investigação denominada Economia da Qualidade. Valceschini \& Berthet (2005) apontam que, diante da nova postura dos consumidores, houve o desenvolvimento de uma grande quantidade de selos e certificações ("grades") que passaram a indicar aos consumidores as características desejadas, garantindo, assim, os atributos ansiados. Além disso, esta nova demanda, por ser mais específica, é mais pessoal e segmentada, o que exige uma reorganização da composição da oferta que, até então, estava focada no abastecimento de um mercado de massa homogêneo.

Valceschini \& Berthet (2005) apontam que este processo de diferenciação permite a segmentação de mercados a partir da diferenciação de produto, uma vez que os consumidores estão mais predispostos a consumir produtos com aspectos peculiares. Sendo assim, tais produtos passam a ter maior valor considerando a percepção de qualidade atribuída pelo consumidor, um fenômeno que a literatura denomina de quase-renda, que é um valor a mais que um produto recebe por apresentar alguma característica peculiar percebida pelos próprios agentes.

Historicamente, o fenômeno descrito acima tem impactado na organização produtiva das cadeias agroalimentares à medida que os agentes tiveram que reorganizar suas rotinas, adaptando-se às exigências de certificações (WILKINSON, 2008). As certificações, por sua vez, se estabeleceram mediante o monitoramento das práticas agrícolas dos produtores e dos seus produtos, ou seja; de processos e produtos. Esses mecanismos de certificação que anteriormente eram de domínio de organismos estatais ou paraestatais foram perdendo espaço para certas organizações privadas. Em nível internacional, esse movimento pode ser observado no acompanhamento das rotinas das grandes centrais de distribuição, como supermercados e estruturas que representam os varejistas globais. Esses agentes passaram a disseminar suas próprias certificações adotando critérios próprios - nem sempre homogêneos para determinados produtos, dando margem ao surgimento de dezenas de selos e certificados internacionais de qualidade (Busch \& Bain, 2004). 
As certificações têm tido um papel importante na coordenação das transações entre os agentes, pois estas se transformaram num mecanismo de mitigação da assimetria de informação. Neste sentido Akerlof (1978) argumenta que o surgimento de determinadas estruturas tem o objetivo de tentar mitigar os efeitos da incerteza sobre a qualidade dos produtos transacionados. Ou seja, a partir da emissão de sinais em direção aos consumidores, esses conseguem interpretá-los diminuindo a assimetria de informação. Especificamente, nos mercados agroalimentares, a emergência dessas estruturas se deu a partir da criação de selos que atestam qualidade e características peculiares dos produtos. (Dörr, 2009; Valceschini \& Berthet, 2005).

Valceschini e Berthet (2005) afirmam que o elemento central da dinâmica do sistema agroalimentar, tanto na produção quanto no processamento dos alimentos, estaria na definição e informação da qualidade através de selos e certificações que poderiam atestar os atributos desses produtos. Para os autores, a emergência de uma padronização no sistema agroalimentar iria além da mitigação da assimetria de informação. Na realidade, a redução de assimetrias seria apenas o fator inicial, uma vez que a ideia de "controle da qualidade total" se alastrou indiscriminadamente por todos os setores produtivos da economia. No setor agroalimentar, este fenômeno teria adquirido maiores contornos na medida em que as formas de coordenação vertical entre os elos produtivos estivessem mais próximas, necessitando assim uma maior compatibilização. Além do mais, a regulação da higiene, segurança do alimento e rastreabilidade permitiriam o surgimento de uma série de normas públicas em consonância com as certificações privadas responsáveis pelas regras de padronização de certos elementos do sistema agroalimentar.

Tendo em vista que o objetivo das certificações é garantir características peculiares do produto, mesmo os aspectos intangíveis (modo de produção, colaboração social, práticas sustentáveis), pode-se afirmar que as mesmas são uma tentativa de diminuir a assimetria de informação entre as partes. Para tanto, as certificações devem estampar confiança e, portanto, é natural que os organismos encarregados de desenvolver as certificações sejam independentes garantindo que os aspectos assegurados pela certificação sejam realmente respeitados (Dörr, 2009).

$\mathrm{O}$ crescimento do movimento em torno das certificações coincide com a abertura do comércio global que se seguiu após a finalização do acordo da Rodada do Uruguai - em 1995, e desencadeou um processo de redução nas barreiras tarifárias do comércio de produtos agrícolas. Nesse mesmo período a Europa vivia uma enorme desconfiança com relação à sanidade dos alimentos comercializados tendo em vista as contaminações, como caso do 'mal da vaca-louca' (bovine spongiform encephalopathy) e o da salmonela em ovos. Em resumo, esses dois eventos combinados foram decisivos para o maior protagonismo privado e $o$ desencadeamento das certificações tripartite 'third-party certifications'(TPC). Diferentemente das diretrizes colocadas pelos "standards" como o Codex Alimentarius, e pelas orientações das autoridades sanitárias de cada país, essas certificações têm padrões estabelecidos pelos grandes varejistas mundiais o que as tornam bastante específicas ao mesmo tempo em que se utilizam de organismos (públicos ou privados) para monitoramento dos produtores espalhados pelo globo. Portanto, as certificações TPC caracterizam-se como arranjos institucionais que 
permitem uma coordenação mais ampla atingindo diversos membros, sem os custos da hierarquização, permitindo certa flexibilidade.

É neste ambiente que em 1997 grandes varejistas europeus constituem um grupo para definição de um conjunto de regras comuns para a produção de FLV. Dessa maneira, a partir das deliberações de um grupo de 13 grandes varejistas, é publicado o protocolo que ficou conhecido como EUREP-GAP (Euro Retailer Produce Working Group for Good Agricultural Practices) em 1999. No início, o protocolo vinculava-se apenas a frutas e vegetais, além disso, era uma legislação aplicada para comercialização nos países europeus que tinham participantes no grupo. No entanto, ao longo do tempo os padrões passaram a abarcar diversos produtos (café, flores e carnes etc.), bem como, passou a ser utilizado por mais de 120 países. Devido a enorme amplitude que o protocolo alcançou, atualmente é denominado GlobalGap (GlobalGap, 2017; Henson et al, 2011) e compreende quatro tópicos principais: segurança dos alimentos, preservação ambiental, saúde e segurança ocupacional e bem-estar animal (Asfaw et al. 2010).

O GlobalGap consolidou um novo padrão de certificação marcando um ponto de inflexão na coordenação das cadeias agrícolas mundiais com a governança passando definitivamente a ser baseada em agentes privados, com o setor público dos países perdendo relevância nas decisões (Hatanaka et al, 2005). Esta maior capacidade de enforcement da legislação privada sobre as cadeias de produtos frescos ficou ainda mais evidente nos países em desenvolvimento, que se consolidaram como importantes supridores das cadeias globais de produtos frescos, os conhecidos NAC's (Newly Agricultural Countries). Esses países passaram então a ter uma importante fonte de dinâmica agrícola tendo em vista a sua inserção nos mercados globais.

Assim as certificações estritamente públicas que monitoravam e regulavam as normas de comercialização (Standards) foram paulatinamente perdendo a sua capacidade de coordenação devido à emergência de novas demandas por parte dos setores compradores, demandas essas que não estão estritamente ligadas à legislação (Grades). Uma dificuldade suplementar é a de que as mudanças tecnológicas e o marco da liberalização do comércio estão levando a um novo formato no comércio de produtos frescos, baseado em cadeias globais de valor com a participação simultânea de diversos agentes em diferentes países. Com isso, alastrou-se em torno das cadeias agrícolas globais uma série de selos e certificações que abordam grande variedade de requisitos, tais como: condições do trabalhador, responsabilidade social, rastreabilidades entre outros aspectos. Empresas varejistas globais como Carrefour, Tesco e outras cadeias de supermercados têm seus próprios selos e suas próprias regras de certificação, mas todas têm um lastro no GlobalGap. Além de aspectos de qualidade dos produtos tais selos são usados pelos atacadistas para diferenciação de produtos frescos. Ao instituir uma relação tripartite complexa que envolve diversos agentes, o arranjo necessita de mecanismos capazes de manter uma coordenação para dificultar o oportunismo que minimize os custos de transação associados.

As certificações têm cumprido um amplo papel na organização dos mercados agrícolas, especialmente dentro das cadeias de produtos frescos. Estas permitem reduzir os custos de transação associados à maior complexidade que envolve as relações entre agentes. No entanto, Hatanaka et al (2005) argumentam que estas 
certificações TPC não se resumem a formas imparciais de coordenar o comércio, pois - mais além, sua adoção em ampla escala tem causado repercussões no ambiente econômico e social e na operação dos agentes inseridos dentro das cadeias agrícolas globais. Em suma, as certificações organizam, reorganizam e disciplinam os envolvidos a partir de relações assimétricas de poder.

\section{Metodologia}

\subsection{Procedimentos adotados}

Para atender o objetivo coletaram-se dados secundários disponíveis sobre produção e comércio internacional de produtos agrícolas em órgãos estatísticos brasileiros e internacionais ${ }^{3}$. Além destes utilizou-se também dados primários coletados a partir de pesquisa de campo, que será esclarecida na seção seguinte. A partir dos dados coletados foi utilizado o método de estatística descritiva para análise da estrutura produtiva e comercial dos Polos irrigados estudados. Além disso, foi adotada uma metodologia de análise de agregação de valor com o objetivo de compreender a dinâmica da cadeia de valor nas exportações das frutas produzidas na região Nordeste. Esta técnica será detalhada em subseção a seguir.

\subsection{Pesquisa de campo}

Foram utilizados dois instrumentos de coleta de dados primários, o primeiro tratase de um questionário aplicado à produtores dos dois Polos alvo de análise deste estudo, que contém perguntas fechadas e foi realizado a partir de uma amostra estatisticamente significante, o procedimento adotado para o cálculo da amostra será esclarecido a subseção seguinte.

Além dos questionários aplicados, também foram realizadas entrevistas semiestruturadas com atores chaves na principal região produtora de manga, o Polo Petrolina-Juazeiro. Os atores entrevistados foram os seguintes: a presidente do Sindicato dos trabalhadores; a presidente do Sindicato dos agricultores familiares; representante do Sindicato patronal; representante dos exportadores de manga (VALEXPORT); 1 grande produtor; 1 médio produtor integrado via cooperativa; 2 médios produtores não integrados; 2 professores da Universidade Federal do Vale do São Francisco que também são médio produtores; 2 pequenos produtores; o diretor geral da Embrapa.

\subsection{Seleção da Amostra}

A pesquisa exploratória do Polo Petrolina-Juazeiro identificou uma área com diversos produtores espalhados em projetos de distritos irrigados. Observou-se ainda

\footnotetext{
${ }^{3}$ Pesquisou-se em bases de dados brasileiras como o portal de comércio exterior SISCOMEX (sistema Aliceweb), estatísticas de política agrícola do MAPA, estatísticas de emprego e desemprego da RAIS e CAGED - Ministério do Trabalho e Emprego e a Agrianual - publicação da empresa FNP. No que se refere às estatísticas internacionais, as principais fontes foram o portal FAOSTAT da FAO - ONU, o Portal Knoema do Banco Mundial, o CEPII - Centre d'études prospectives et d'informations internationales da França e o USDA - Departamento de Agricultura dos Estados Unidos, ITC International Trade Center e portal www.mysupermarket.co.uk do Reino Unido, em relação aos preços de vendas de frutas.
} 
que os perímetros Nilo Coelho e Maria Tereza, no município de Petrolina, seriam os mais relevantes, pois além destes serem, em conjunto, a maior área irrigada da região - e assim concentrar grande parte dos produtores - estes perímetros, diferente dos demais, tem uma maior predominância de produtores de uva e manga, as quais foram as selecionadas como foco de análise desta tese. Estes dois projetos possuem uma área irrigada de 23.043 hectares (DINC, 2014).

Segundo levantamento da administração do Distrito Irrigado Nilo Coelho, existem cerca de 2.058 produtores de uva e/ou manga nos perímetros Nilo Coelho e Maria Tereza. Deste modo, a partir desta população, buscou-se retirar uma amostra representativa através de uma amostra aleatória simples como demonstra a fórmula abaixo.

Onde:

$$
\mathrm{n}=\frac{\mathrm{Np}(1-\mathrm{p}) \mathrm{Z}^{2}}{\mathrm{p}(1-\mathrm{p}) \mathrm{Z}^{2}+(\mathrm{N}-1) \mathrm{e}^{2}}
$$

n: é a amostra retirada da população

$\mathrm{N}$ : é o tamanho da população

Z: é o nível de confiança associada a uma variável normal

p: probabilidade do evento ocorrer

e: é o erro amostral

Para este trabalho, foram utilizados os seguintes valores: conhecendo o tamanho de 2058 produtores de Uva ou Manga dos perímetros, utilizamos um nível de confiança (Z) de $90 \%$ e um erro amostral de $6 \% 4$, associado à probabilidade de $50 \%$ da chance do evento ocorrer. Deste modo, obteve-se que seriam necessários cerca de 179 questionários aplicados para se extrair uma amostra representativa da população, segundo os critérios adotados. Assim, foram aplicados 180 questionários nos perímetros Nilo Coelho e Maria Tereza.

Diferentemente do Polo Petrolina-Juazeiro, os produtores estão numa área muito mais dispersa e não existem órgãos públicos que aglutinem estes produtores. Deste modo, para realizar a aplicação dos questionários, buscou-se contato com a associação de produtores de Melão do Polo, a COEX, a qual forneceu uma lista com 19 produtores de melão da região. Assim, durantes os meses de outubro e novembro de 2014 foi feito contato com todos os produtores, porém, apenas 12 deles puderam/quiseram responder os questionários.

\subsection{Agregação de Valor}

Cada etapa produtiva envolve um processo de investimentos, custos e lucros. Assim, como aponta Araújo (2007) à agregação de valor está vinculada à maior sofisticação do produto. Observando as cadeias agrícolas, este processo de valorização pode está ligado tanto à apresentação do produto in natura, exaltando alguma característica específica desejada por um mercado consumidor como também, através de algum tipo de processamento na conveniência do consumidor. Para captar as etapas de agregação de valor desde dentro da porteira de produção

\footnotetext{
${ }^{4}$ Este percentual de erro amostral atribuído no cálculo da amostra foi atribuído tendo em vista o escasso recurso financeiro do autor no processo de coleta de dados. Este foi o menor percentual que tornaria a pesquisa possível.
} 
até o valor pago pelo consumidor final foram utilizados os seguintes procedimentos metodológicos.

No caso do melão colheu-se o preço do quilo pago pelo consumidor final a partir de dados do site <http://www.mysupermarket.co.uk> que disponibiliza a variação de preços dos produtos nas principais redes de supermercados do Reino Unido. Por sua vez no estudo da manga os dados ao consumidor final foram coletados da base de dados do USDA.

A margem de lucro do supermercado é calculada pela diferença do preço pago pelo consumidor do preço no atacado, como demonstra a equação 1. O preço no atacado do melão no mercado internacional foi baseado nos relatórios mensais do International Trade Center (ITC), uma agência sob a tutela conjunta da ONU e OMC.

Margem do supermercado = Preço varejo - preço atacado 1

Deste modo, o atacadista tem sua margem de comercialização extraída da diferença de seu preço de venda e o preço CIF do melão exportado pelo Brasil. Tratando-se de transações internacionais a divulgação do valor envolvendo determinado fluxo comercial se apresenta de duas maneiras. Uma apresenta o valor da transação sem os custos de seguros, taxas aduaneiras e fretes, este é o preço Free on Board (FOB). Esta informação é divulgada pelo país exportador que declara o valor a partir desta ótica. A segunda maneira de divulgação é incorporando os valores de custos, fretes e taxas valor CIF ou "Cost, Insurance and Freigth", seu valor é normalmente divulgado pelas declarações do importador.

Portanto, como ilustra a equação 2, a diferença entre o valor CIF e FOB são os gastos com os fretes, seguros e taxas.

$\mathrm{CIF}$ value $-\mathrm{FOB}$ value $=$ costs of freights, insurances and taxes

Os valores FOB e CIF foram retirados da base de dados da CEPII que divulga a quantidade total exportada e os valores declarados FOB e CIF.

A partir da divisão do valor total da exportação de país i para um país j dividido pela quantidade total exportada é possível encontrar uma proxy para preço por kg transacionado tanto FOB quanto CIF como demonstram as equações 3 e 4 a seguir.

$$
\sum \frac{x_{i, j}}{q_{i, j}}
$$

De maneira análoga pode-se definir também a proxy de preço pago pelo importador:

$$
\sum \frac{x_{j, i}}{q_{i, j}}
$$

Deste modo, considera-se o preço FOB o valor recebido pelo produtor. Sendo assim, parte-se para outra etapa da análise da agregação de valor dentro da porteira, a partir dos custos de produção. Os custos de produção utilizados aqui foram retirados da publicação Agrianual contém valores referentes para a produção de melão da área de Mossoró e manga na área do Polo Petrolina-Juazeiro.

A partir destes dados é viável estimar os custos de produção por kg de melão produzido. E a partir da subtração do preço recebido por kg de melão é possível conhecer a margem do produtor. 
Após desagregar todas estas etapas permite-se calcular a participação de cada estágio da cadeia produtiva do melão no valor final (margens, insumos, trabalho) e observar que agentes se apropriam da maior parcela de valor gerado dentro da cadeia de produção.

No entanto, é importante destacar uma sutileza nos mercados finais, uma parte dos produtos (manga e melão) é comercializada em unidade inteira. Entretanto, outra parte é comercializada a partir de um processamento mínimo sem perder as características naturais.

Para obter maior compatibilidade e permitir comparação todos os valores foram convertidos em dólar. Assim, os custos de produção disponibilizados em reais foram transformados em dólar utilizando a taxa de câmbio média do período. Os valores FOB e CIF obtidos a partir da base de dados da CEPII já estavam em dólar. No entanto, os valores de preços aos atacadistas do ITC e os preços dos supermercados do Reino Unido estavam em libras e, portanto, também foram convertidos para dólar utilizando uma taxa de câmbio média libra/dólar para o período.

\section{Certificações nos Polos De Fruticultura do Nordeste}

\subsection{A Produção de Frutas para Exportação no Nordeste Brasileiro}

A consolidação do mercado internacional para os FLV's foi um fator preponderante para a solidificação dos polos de produção de frutas irrigadas do Nordeste. A materialização deste mercado internacional foi possível devido a ação de novos atores que passaram serem protagonistas no processo de distribuição, especialmente as redes de supermercados passaram a ter uma supremacia no processo de comercialização e mundialização dos produtos, como apontam diversos autores (Bursch \& Lawrence, 2005; McMichael, 2007; Lang \& Heasman, 2015).

O Polo Petrolina-Juazeiro especializou-se na produção de frutas a partir da infraestrutura propiciada pelas obras hídricas, possibilitando a irrigação de cerca de 100 mil hectares naquela região (Silva, 2001). Destacam-se, na região, as culturas de uva de mesa e da manga, com participação de $99 \%$ e 90\% da exportação nacional desses produtos, respectivamente. O Polo apresenta uma estrutura de comercialização diversificada dirigida tanto para o mercado internacional quanto para o mercado interno (Sobel, 2011; Cavalcanti, 1999). Por sua vez, o Polo AçúMossoró se caracteriza, principalmente, pela forte especialização na produção de melão, tendo cerca de 12 mil hectares desta cultura sendo cultivados, o que representa aproximadamente $15 \%$ da sua área. 
Figura 1 - Polos Irrigados do Nordeste

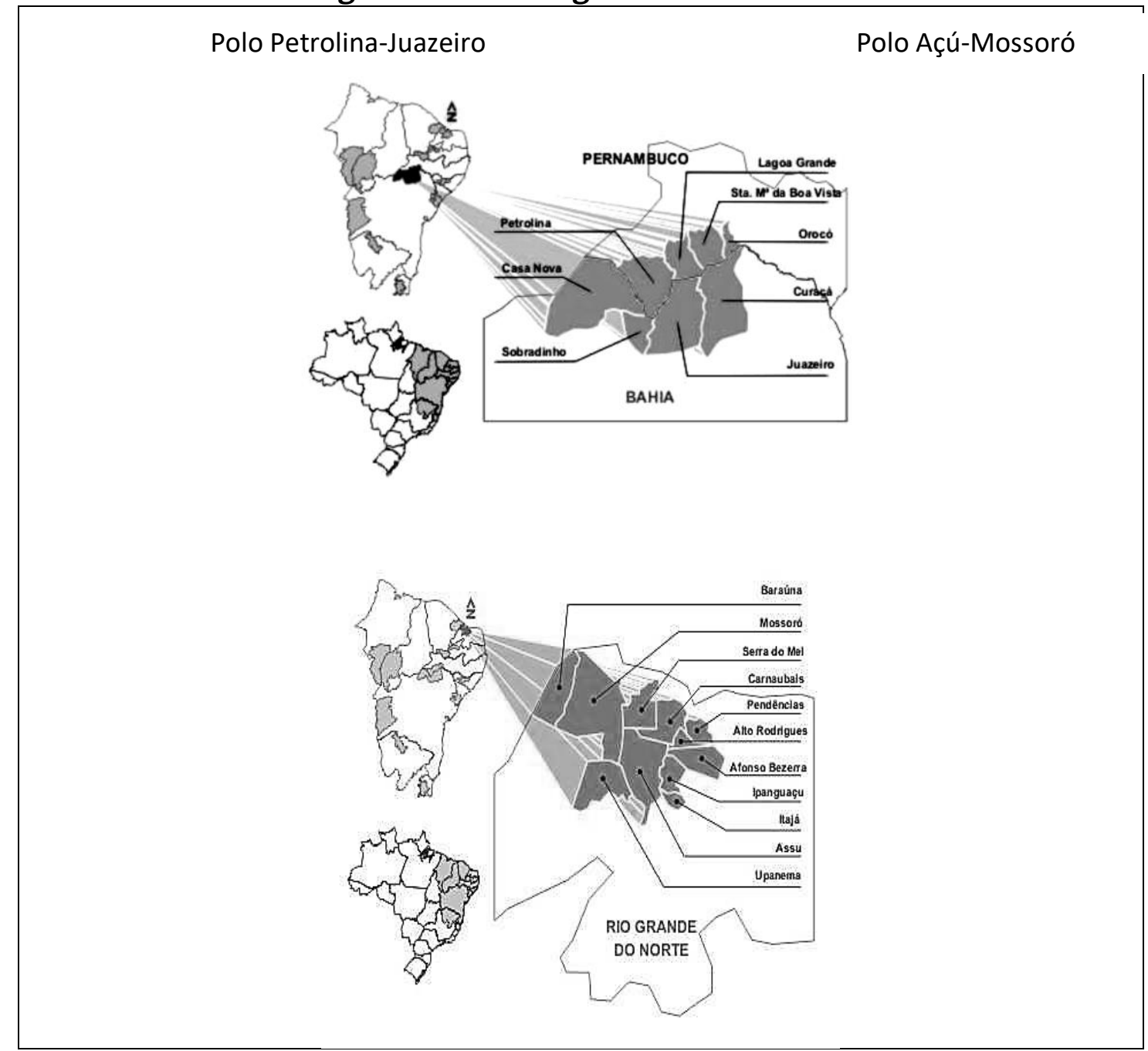

Fonte: Ortega e Sobel (2005); Nunes (2009).

Ao longo das últimas décadas estes dois Polos se especializaram na oferta de frutas in natura para o mercado internacional, o que implicou em um esforço logístico garantindo o suprimento na contra estação, aproveitando a janela que se abre no período de inverno no hemisfério norte. A organização dos polos como integrantes de cadeias globais de suprimento envolveu uma série de agentes diferenciados à montante e à jusante no processo de produção de frutas.

\subsection{O impacto das certificações na coordenação dos mercados de frutas dos Polos Irrigados do Nordeste}

As formas de organização da produção, como já abordado anteriormente, são reflexos das estruturas de mercados, dos tipos de produtos transacionados e das características dos agentes envolvidos. Assim, a alta especificidade dos ativos, seja na produção ou na transação, requer maior coordenação e, por isso, tendem à maior especialização (Sexton \& Lavoie, 2001).

A presença de maior especificidade dos ativos reconhecida nos mercados agrícolas é, em grande medida, consequência deste novo sistema agroalimentar. 
Como já discutido neste artigo, alguns consumidores têm maior preço de reserva para produtos que englobam certas características peculiares. Logo, esses produtos passam a agregar certo valor a partir dessas características criadas/percebida pelos agentes, o que é conhecido, na literatura, como quase-renda (Saes, 2007). Diante disso, selos e certificações que designam qualidade, origem e especificidade de determinado produto passaram a ter um papel relevante na inserção competitiva de tais produtos (Belik, 2007; Belik \& Chaim, 1999).

A tabela 1 exibe alguns aspectos dos produtos em análise nos dois Polos alvo deste trabalho, que, em certa medida, despertam algum grau de especificidade, podendo gerar quase-rendas. Assim, observa-se que existe um grau de especificidade considerável nestes produtos, porém se manifestam de maneiras distintas. No Polo Petrolina-Juazeiro existe um baixo índice de produtores com certificação, apenas $20,56 \%$. Este fato sugere que os mercados com os quais a maioria dos produtores deste Polo transaciona não utilizam o mecanismo de certificação como instrumento para assegurar alguma peculiaridade importante. Consequentemente, isso indica que os consumidores finais não têm um grau de exigência elevado para aspectos intangíveis dos produtos, que só poderiam ser assegurados por certificações críveis. A falta de exigência de certificação implica, como consequência, numa baixa taxa de monitoramento no Polo Petrolina-Juazeiro, apenas $27,7 \%$.

Tabela 1 - Especificidades dos Produtos Transacionados pelos Agentes do Polo Petrolina-Juazeiro e Açú-Mossoró

\begin{tabular}{cccccc}
\hline \multirow{2}{*}{ Aspectos } & \multirow{2}{*}{ Relevância } & \multicolumn{2}{c}{$\begin{array}{c}\text { Polo Petrolina- } \\
\text { Juazeiro }\end{array}$} & \multicolumn{2}{c}{ Polo Açú-Mossoró } \\
\cline { 3 - 6 } & & $\%$ & $\mathbf{n}$ & $\%$ & $\mathbf{n}$ \\
\hline \multirow{2}{*}{ Possuí Premiação } & Sempre & $66,7 \%$ & 120 & $8,3 \%$ & 1 \\
& Nunca & $31,7 \%$ & 57 & $83,3 \%$ & 10 \\
& Às Vezes & $1,7 \%$ & 3 & $8,3 \%$ & 1 \\
\hline Existe Monitoramento & Sim & $27,2 \%$ & 49 & $58,3 \%$ & 7 \\
\hline Possuí Certificação & Sim & $20,6 \%$ & 37 & $75 \%$ & 9 \\
\hline
\end{tabular}

Fonte: Elaborado a partir dos dados da Pesquisa de Campo.

Apesar de no Polo Petrolina-Juazeiro a maioria dos produtores transacionar com mercados que não exigem tantas garantias de especificidades intrínsecas ao produto, não se pode afirmar que esses produtos do Polo não possuem algum grau de especificidade. Analisando a tabela anterior, percebe-se que as especificidades têm sido reconhecidas no Polo Petrolina-Juazeiro através de premiações por qualidade da fruta, as quais são identificadas pelos compradores e, assim, passam a fazer uma espécie de rating, pagando um preço mais elevado pelas frutas que apresentam melhores características. No entanto, os atributos requeridos pelos mercados destes produtos concentram-se nos aspectos visuais (cor, tamanho, aparência)

Por sua vez, o Polo Açú-Mossoró tem incorporado as especificidades dos seus produtos de maneira oposta, de modo que as premiações têm pouca importância na coordenação dos acordos entre os agentes, apenas um pouco mais de $15 \%$ dos produtores em algum momento utilizam mecanismos de premiação nas suas transações. Todavia, as certificações, assim como o monitoramento, têm sido 
utilizadas de forma ampla na coordenação das transações no Polo. Como demonstra a tabela 1, a certificação está presente em $75 \%$ dos produtores e o monitoramento é realizado em quase $60 \%$.

Estas particularidades entre os produtores no Polo relacionam-se com os mercados acessados pela maior parte dos produtores. Observa-se que mais de $90 \%$ dos produtores destinaram toda sua produção para o mercado doméstico, enquanto uma parcela de $3 \%$ dos produtores destina $100 \%$ da sua produção para exportação. 


\section{Gráfico 1 - Percentual da Produção de Manga Destinada pelos Produtores para Exportação e Mercado Interno}

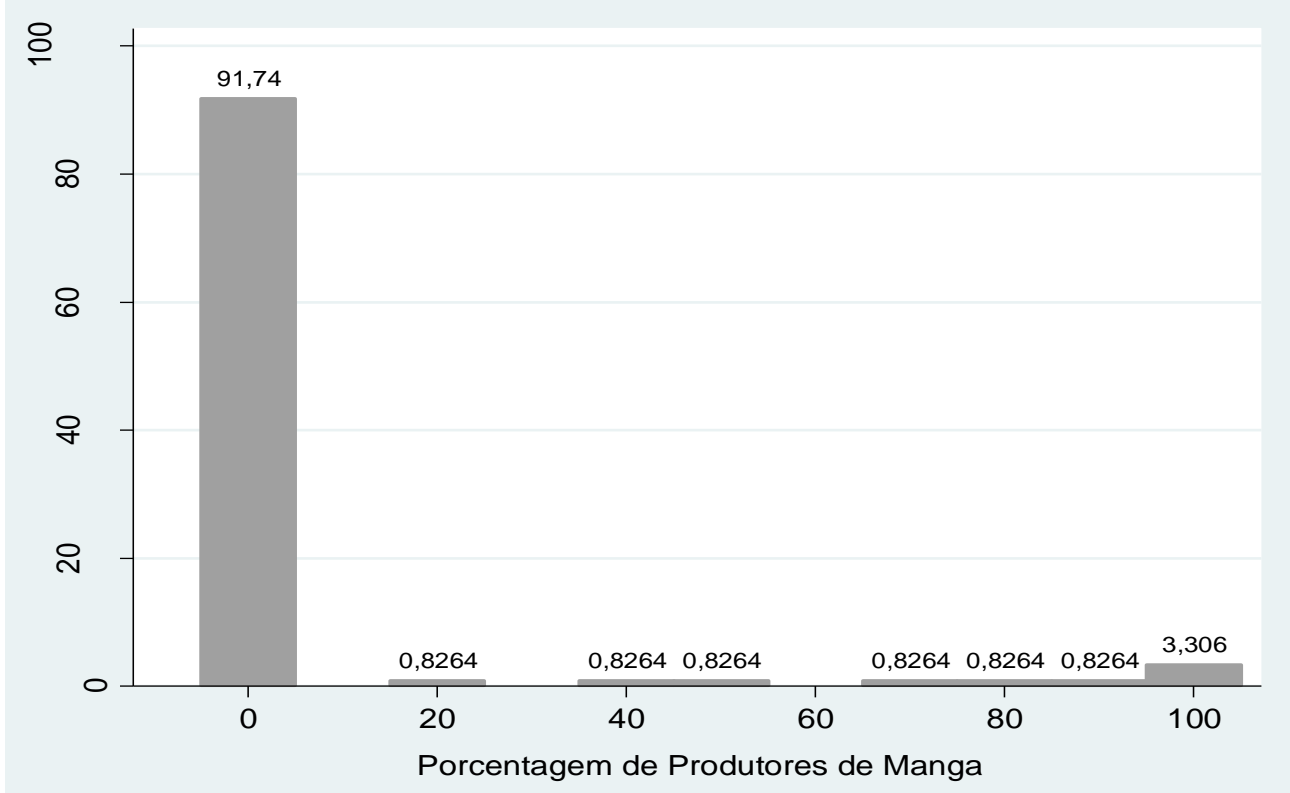

Fonte: Elaborado a partir dos dados da Pesquisa de Campo

Todavia, no Polo Açú-Mossoró, mais de $50 \%$ dos produtores de melão destina $50 \%$, ou mais, de sua produção para exportação, enquanto aqueles que negociam apenas no mercado interno representam 33\%.

\section{Gráfico 2 - Percentual da Produção de Melão Destinada pelos Produtores para Exportação e Mercado Interno}

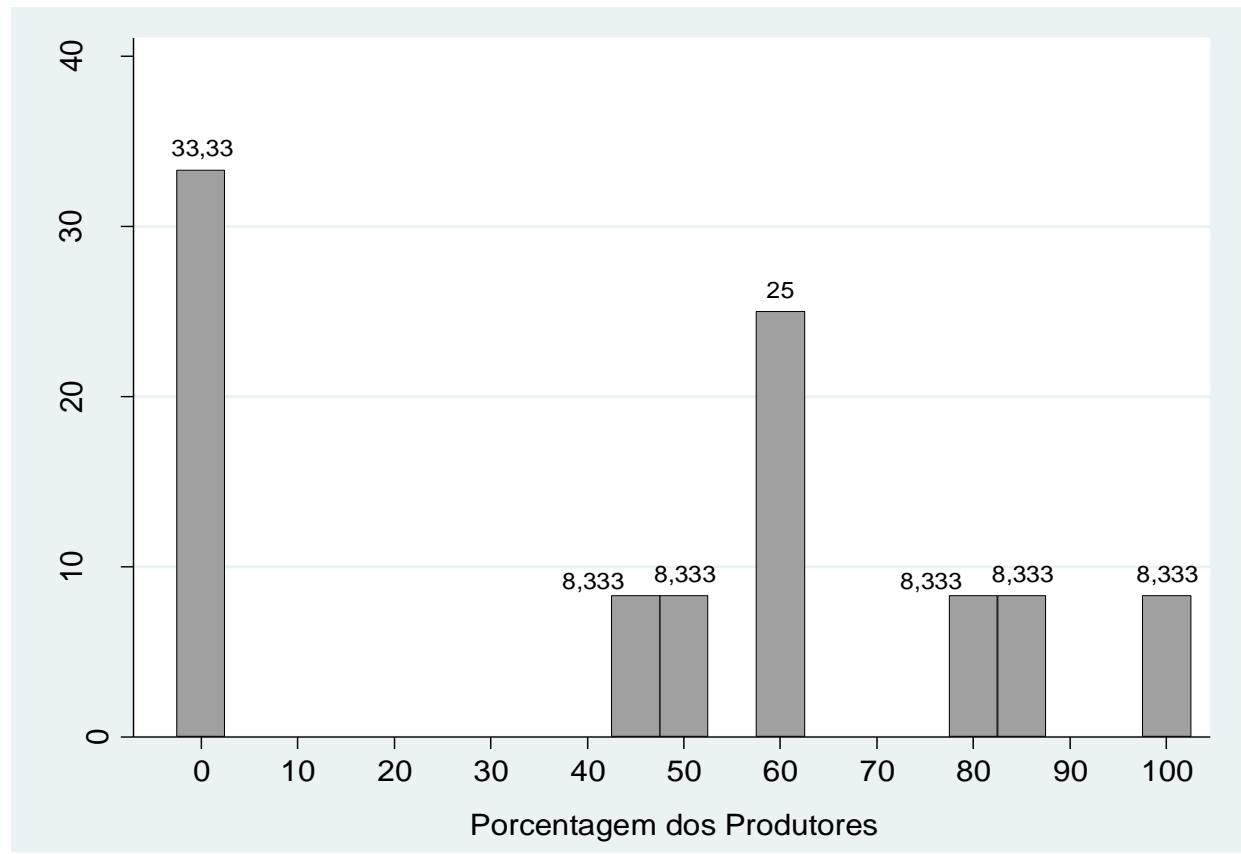

Fonte: Elaborado a partir dos dados da Pesquisa de Campo.

Um ponto a ressaltar que pode explicar, pelo menos em parte, a maior participação do mercado doméstico no escoamento das frutas, principalmente no Polo Petrolina-Juazeiro, são os menores custos associados à sua comercialização. A 
exportação, normalmente, envolve seguros de carga no transporte, assim como possui um valor de frete bem mais elevado. Além disso, em termos de custos em transação, tem-se um maior grau de incerteza. Ademais, os mercados internacionais são mais exigentes em relação às certificações - principalmente o mercado europeuas quais representam não só custos para adaptar a produção às exigências, mas, principalmente, a necessidade de contratação de empresas que atestem a certificação conjuntamente com o pagamento do selo em si. Estes elevados custos de transação passam a ser impeditivos para produtores de pequena escala e menor rentabilidade, que são maioria no Polo Petrolina-Juazeiro, como aponta Penha (2018). Nesse sentido, o mercado interno apresenta possibilidades de menores custos de comercialização e produção.

Os custos de transação mais elevados nas comercializações internacionais decorrem da maior assimetria de informação e maiores chances de oportunismo. Este fato implica em grande medida numa necessidade de maior coordenação na cadeia de produção, distribuição e comercialização. É neste sentido mais amplo que as certificações têm representando um papel importante neste novo sistema agroalimentar. Portanto, as certificações não definem apenas os padrões de exigência. Analisando de perto estas coordenam a cadeia de valor de modo que os atributos desejáveis que o consumidor final disposto a pagar o valor a mais esteja presente. Por conseguinte, as certificações são instrumentos que permitem apropriação do valor gerado dentro da cadeia de valo. Assim, como são mecanismos criados e regulados em grande maioria pelas redes varejistas, estas permitem que estes atores se apropriem do valor que elas retêm.

Tal movimento evidencia-se ao analisar-se o processo de agregação de valor ao longo da cadeia de produção das duas principais frutas exportadas pelos polos. Além disso, é possível identificar quais elos da cadeia conseguem apropriar a maior parcela do valor gerado ao longo da cadeia.

No caso do melão foi analisado o valor adicionado na cadeia que tem como destino final o mercado Britânico, uma vez que a região é uma dos principais destinos do melão produzido no Polo Açú-Mossoró.

Como demonstra a tabela 2, o valor final médio pago nos supermercados do Reino Unido no ano de 2015 foi de cerca de US\$1,20. O que chama atenção nesta cadeia é o baixo valor capturado pelas redes de supermercados quando o produto é vendido de forma integral in natura, com uma margem de contribuição de 0,02 centavos de dólares por quilo. Em solo europeu as redes de atacadista se apropriam de maior parcela, cerca de 0,16 centavos de dólares por Kg. 


\begin{tabular}{lccc}
\multicolumn{2}{c}{ Tabela 2 - Agregação de Valor na Cadeia de Melão in Natura no Reino Unido (em } \\
US\$\$ de 2015) & & \\
\hline \multicolumn{1}{c}{ Agentes } & $\begin{array}{c}\text { Melão } \\
\text { Inteiro }\end{array}$ & Melão Fatiado & Fonte do dado \\
\hline $\begin{array}{l}\text { Preço Supermercado } \\
\text { Margem de lucro do }\end{array}$ & 1.20 & 4.31 & My supermarket \\
$\quad$ supermercado & 0.02 & 3.13 & \\
Preço Atacado & 1.18 & 1.18 & ITC \\
$\quad$ Margem de Lucro do & 0.16 & 0.16 & \\
atacadista & 1.02 & 1.02 & CEPII \\
Cif $\quad 0.22$ & 0.22 & CEPII \\
Seguros, frete e taxas & 0.80 & 0.80 & \\
Fob (preço ao produtor) & 0.54 & 0.54 & Agrianual \\
Margem do Produtor & 0.01 & 0.01 & Agrianual \\
Impostos/Taxas & 0.01 & 0.01 & Agrianual \\
Agrônomo & 0.01 & 0.01 & Agrianual \\
Administração & 0.16 & 0.16 & Agrianual \\
Insumos Agrícolas & 0.04 & 0.04 & Agrianual \\
Máquinas & 0.04 & 0.04 &
\end{tabular}

Fonte: Elaboração própria

Observa-se que $66 \%$ do valor final é gerado dentro da porteira, sendo que grande parte é a margem de contribuição do produtor. No entanto, esta margem do produtor não é o lucro líquido auferido pelo mesmo, mas sim a margem bruta que inclui custos intangíveis de difícil mensuração como os custos de transação associado a governança. Portanto, é provável que a margem líquida seja bem inferior, uma vez que os produtores dos polos irrigados de fruticultura enfrentam custos de transações consideráveis, como demonstra Penha (2018). Além disso, é interessante notar o fraco desempenho na agregação de valor por parte das redes de supermercados no produto final, o que é um contraponto a literatura que reforça o poder das redes de supermercados dentro dos mercados agrícolas, como ressaltado ao longo deste trabalho. Vale destacar também que os melões consumidos nos mercados europeus raramente são adquiridos de maneira integral. Grande parte do melão é consumida em pequenas porções disponibilizadas pelas redes de supermercados que sofrem um mínimo de processamento, mas não perdendo seu apelo natural de frescor.

Percebe-se que neste tipo de mercado a margem de contribuição das redes de supermercado cresce de maneira significativa, quase quadriplicando o valor final do produto em relação ao melão ao kg do melão vendido de maneira integral. Assim, realizando este mínimo processamento as redes de supermercados conseguem se apropriar de mais de $70 \%$ do valor do produto. Enquanto que o produtor tem sua participação reduzida para pouco mais de $10 \%$.

Por sua vez na cadeia da manga produzida no Polo Petrolina-Juazeiro a dinâmica repete-se. Neste caso foi analisado o processo de agregação de valor na manga exportada para os Estados Unidos. No mercado final americano foi observado tanto no consumo do fruto inteiro, como com algum beneficiamento, mas sem 
perder as propriedades naturais. A tabela 3 abaixo ilustra que as redes varejistas conseguem agregar valor fazendo um mínimo de beneficiamento e assim se apropriar dos atributos intrínsecos as frutas frescas, como frescor, valor nutricional, além de outros atributos reconhecidos nestes mercados.

Tabela 3 - Agregação de Valor na Cadeia da Manga no Mercado Estadunidense (em US\$ de 2016)

\begin{tabular}{lccc}
\hline KG/US\$ & Inteiro & Beneficiado* & $\begin{array}{c}\text { Fonte do } \\
\text { Dado }\end{array}$ \\
\hline Varejistas & 2.91 & 22.40 & USDA \\
Margem de lucro do supermercado & 0.43 & 19.92 & \\
Preço Atacadista & 2.48 & 2.48 & ITC \\
Margem de Lucro do Atacadista & 0.16 & 0.16 & \\
Preço CIF & 2.32 & 2.32 & CEPII \\
Fretes, seguros e taxas & 1.29 & 1.29 & \\
Preço FOB (Preço ao Produtor) & 1.03 & 1.03 & CEPII \\
Margem do Produtor & 0.84 & 0.84 & \\
Custo Total & 0.19 & 0.19 & Agrianual \\
Trabalhadores & 0.03 & 0.03 & Agrianual \\
Máquinas & 0.04 & 0.04 & Agrianual \\
Insumos Agrícolas & 0.07 & 0.07 & Agrianual \\
Custos Administrativos & 0.05 & 0.05 & Agrianual \\
\hline
\end{tabular}

Fonte: Elaboração própria

*Trata-se de uma média de preços praticados em todo território americano de várias formas de comercialização de manga in natura com algum beneficiamento, inclui manga desidratada, pedaços e fatias.

\section{Considerações Finais}

Este trabalho buscou apresentar qual o papel desempenhado pelas certificações do tipo TPC na coordenação dos mercados agrícolas e como estas têm impactado nas relações de trabalho. No entanto, para atingir este objetivo este trabalho aportou-se numa extensa literatura que desse embasamento para entender como estas certificações têm atuado nos mercados globais a partir de sua gênese.

Percebe-se que os mercados agrícolas passaram por uma profunda transformação, em que as cadeias de supermercados passaram a ter maior preponderância na coordenação dos mercados alterando as relações com os produtores. Neste novo mercado os produtores para consumo fresco apresentam um valor ao consumidor elevado, sendo assim os agentes buscam formas de coordenação dos mercados que busquem satisfazer as especificidades dos agentes. É neste cenário que as certificações têm tido um papel crucial para garantir aspectos intrínsecos que garanta a captação das quase-rendas. Estas certificações são selos privados criados pelas redes varejistas, mas que contam com a participação de órgãos públicos e privados para que possam assegurar sua extensão e aplicabilidade.

O impacto destas certificações nas cadeias agrícolas tem sido bastante discutido e observa-se que no setor de FLV em particular no caso das frutas tropicais produzidas no Nordeste, esta tem um papel central de coordenar o processo de produção, distribuição e comercialização. Uma vez que define os padrões técnicos e 
normas éticas de produção, bem como, consegue se apropriar das quase-rendas geradas dentro da cadeia, principalmente quando a fruta sofre algum beneficiamento simples.

\section{Referências}

AGRIANUAL, F. N. P. Anuário da agricultura brasileira. São Paulo, OESP Gráfica, 2016.

AKERLOF, GEORGE A. "The market for "lemons": Quality uncertainty and the market mechanism." In Uncertainty in Economics, pp. 235-251. 1978.

ASFAW, S., MITHÖFER, D., \& WAIBEL, H. Agrifood supply chain, private-sector standards, and farmers' health: evidence from Kenya. Agricultural Economics, 2010.

BALDWIN, R. Global Supply Chains: Why they emerged, why they matter and where they are going In:Global value Chains in Changing World Deborah K. ELNS \& Patrick LOW (eds). WTO: Geneve, 2013.

BARZEL, Y. Measurement cost and the organization of markets. Journal of law and economics, v.25, n.1 , p. 27-48, 1982.

BELIK, W. \& CHAIM, N. A. Formas híbridas de coordenação na distribuição de frutas, legumes e verduras no Brasil. Revista Cadernos de Debate v.7, p.1-9., 1999.

BELIK, W. Agricultura, concentração no setor de comercialização e novos espaços para a distribuição de produtos frescos, Economia Ensaios. vol. 22. Uberlândia: UFU, 2007.

BUSCH, L., \& BAIN, C. New! Improved? The Transformation of the Global Agrifood System. Rural Sociology, v. 69, n. 3, pp. 321-346, 2004.

CEPII. Working Paper N²011-10, April 2011. Diponível em: < http://www.cepii.fr/CEPII/en/bdd_modele/presentation.asp?id=2>.

CORIAT, BENJAMIN. Globalization, Variety and Mass Production: The Metamorphosis of Mass Production in The New Competitive Age In: Hollingsworth, J. R. \& Boyer, R. Contemporary Capitalism: The Embeddedness of Institutions. Cambrige: Cambridge University Press, 1997.

DOLAN C, HUMPHREY J. Governance and trade in fresh vegetables: the impact of UK supermarkets on the African horticulture industry. Journal of development studies. 2000 Dec 1;37(2):147-76.

DÖRR, A. C. Economic analysis of certification in the Brazilian fruit chain. Göttingen: Cuvillier Verlag Göttingen, 2009 p. 224. 
DUPUIS, E., GOODMAN,D AND HARRISON, J.. "Just values or just value? Remaking the local in agro-food studies." In Between the Local and the Global, pp. 241-268. Emerald Group Publishing Limited, 2006.

FARINA, E M.M. Q \& REARDON, T. Agrifood Grades and Standards in the extended Mercosur; Their Role in the Changing Agrofood System. Annual Meeting of AAEA Tampa Florida, 2000

FARINA, E. M.Q. \& Zylberstajn, D. Deregulation, chain differentiation and the role of government, Paper presented at the First Brazilian Workshop of Agri-Chain Management - November 10 and 11, Ribeirão Preto: FEA -USP, 1997.

FONTE, M. Food Relocalisation and Knowledge - Dynamics for sustainability in Rural Areas In: Maria FONTE \& Apostolos G. PAPADOPOULOS (eds.) Naming Foods After Places, pp 1-35, Ashgate 2010

FRIEDMANN, HARRIET. "Distance and durability: Shaky foundations of the world food economy." Third World Quarterly13, no. 2 (1992): 371-383.

FUNCKE, A.; MIRA, E.; MASCARENHAS, G., \& PEREIRA, P. Sitema Produtivo 04: Perspectivas do Investimento em Agronegócio, Rio de Janeiro: UFRJ, 2009.

GLOBALGAP (2017). Disponível em:

http://www.globalgap.org/.content/.galleries/documents/160506_Fruit_and_Vegeta bles_Booklet_en.pdf. Acesso em 02 de outubro de 2017.

GEREFFI G, HUMPHREY J, STURGEON T. The governance of global value chains. Review of international political economy. 2005 Feb 1;12(1):78-104.

GOODMAN, D. Espaço e lugar nas redes alimentares alternativas: conectando produção e consumo. In: Marcio GAZOLLA \& Sergio SCHNEIDER (orgs.) Cadeias Curtas e redes Agroalimentares Alternativas: negócios e mercados da agricultura familiar. Porto Alegre: Editora UFRGS, pp 59-82, 2017

GWYNNE R N. Globalisation, commodity chains and fruit exporting regions in Chile. Tijdschrift voor economische en sociale geografie. 1999 May;90(2):211-25.

HATANAKA M, BAIN C, BUSCH L. Third-party certification in the global agrifood system. Food policy. 2005 Jun 1;30(3):354-69.

HENSON S, MASAKURE O, CRANFIELD J. Do fresh produce exporters in sub-Saharan Africa benefit from GlobalGAP certification?. World Development. 2011 Mar 1;39(3):375-86.

HLPE. Nutrition and food systems. A report by the High Level Panel of Experts on Food Security and Nutrition of the Committee on World Food Security, Rome: 2017 
INTERNATIONAL TRADE CENTER (ITC). Price information updates and market dynamics. Disponível em:< http://www.intracen.org/itc/market-insider/fruits-andvegetables/price-information-updates/>

JHA, P. \& CHAKRABORTY, A. Post-fordism, Global Production Networks and Implications for labor - Some case Studies from national Capital Regim India. ISID Working Paper 172. New Deli nov 2014

KLEIN, B.; CRAWFORD, R. G. \& ALCHIAN, A. A. Vertical integration, appropriable rents, and the competitive contracting process. Journal of law and economics, n.2 , v. 21, p. 297-326, 1978.

LANGLOIS, R. N. \& Fos, Nicolai J. Capabilities and Governance: The rebirth of Production in the Theory of economic Organizations. Working Paper DRUID 97-2, 1998.

MARSDEN, T. et al. The road Towards Sustainable Rural Development: issues on Theory, Policy and Research Practice. Joutrnal of Environmental Policy \& Planning 3, pp 75-83, 2001

MARSDEN, T. Mobilities, Vulnerabilities and Sustainability: Exploring pathways from Denial to Sustainable Rural Developments. Sociologia Ruralis, Vol 49 (2) April 2009 pp 113-132

MENARD, C. Why organisations matters: a journey away from the fairy tale. Atlantic Economic Journal Vol 24 dec 1996 no. 4 pp281-300

NUNES, E. M. Reestruturação agrícola, instituições e desenvolvimento rural no nordeste: as dinâmicas regionais e a diversificação da agricultura familiar no polo Assu-Mossoró (RN), Porto Alegre: UFRGS, 2009.

ORTEGA, A. \& SOBEL, T. Desenvolvimento territorial nos Perímetros de Irrigação do Submédio do Vale do São Francisco (PE/BA): avaliação preliminar. In: XLIII CONGRESSO DA SOBER. 2005.

OSTROM, E. Governing the Commons. The Evolution of Institutions for Collective Action. Cambridge: Cambridge University Press, 1990

OXFAM. Analysis of German Banana Value Chains and Impacts on Small Farmers and Workers (Germany: Oxfam), 2014.

PENHA, T.; BELIK, W.; MATOS FILHO, J; OLIVEIRA, G.. Measuring value capture along the Brazilian melon value chain. In.: Decent work deficits in southern agriculture: measurements, drivers and strategies. Eds. Christoph Scherrer \& Santosh Verma, 2018. 
PENHA, T.; Estrutura e Dinâmica do Sistema Agroalimentar Mundial: Uma Análise dos Mercados de Fruticultura dos Pólos Irrigados de Açú-Mossoró e PetrolinaJuazeiro. Mauritius: Novas edições acadêmicas, 2018.

PLOEG, J. D. Van der. The Food Crisis, Industrialized Farmingand the Imperial Regime. Journal of Agrarian Change Vol. 10 No. 1, January 2010, pp. 98-106, 2010 ROBERTS, P. The End of Food. Boston: Houghton Mifflin, 2008

SAES, M. S, M,. A distribuição de quase-renda e a estratégia de diferenciação no café. Revista de Administração Contemporânea, v. 11, n. 2, p. 151-171, 2007

SYLVANDER, B. Conventions de qualité, marchés et institutions: Le cas de produits de qualité specifique In: François NICOLAS \& Egyzio VALCESCHINI (eds.)

Agroalimentaire: une economie de la Qualité. Paris: INRA, pp.167-184, 1995.

TOREY, H. Local Food as a Contested Concept; Networks, Knowledge, Nature and Power in Food based Strategies for Local Development In: Maria FONTE \& Apostolos G. PAPADOPOULOS (eds.) Naming Foods After Places, pp 39-53, Ashgate. 2010

USDA. Disponível em: https://www.ers.usda.gov/data-products/fruit-and-vegetableprices/

VALCESCHINI, E. \& BERTHET, E. Product quality and agri-food markets: Scientific knowledge and research perspectives. European Review of Agricultural Economics, v. 32, p. 3, 2005.

WILKINSON, J. Mercados, redes e valores: o novo mundo da agricultura familiar. Porto Alegre: UFRGS, 2008.

Thales Augusto Medeiros Penha. Professor do Departamento de Economia na Universidade Federal do Rio Grande do Norte (UFRN). Doutor em Desenvolvimento Econômico pelo Instituto de Economia da Universidade Estadual de Campinas (Unicamp).Mestrado e graduação em Economia pela Universidade Federal do Rio Grande do Norte. Pesquisa temas relacionados: Nova Economia Institucional, contratos e governança nos mercados agrícolas. thalesaugusto_07@hotmail.com

Walter Belik. Professor Titular do Instituto de Economia da Universidade Estadual de Campinas (Unicamp) e Visiting Lecturer na Universidade de Kassel, Alemanha. Possui graduação em Administração de Empresas pela Escola de Administração de Empresas de São Paulo da Fundação Getúlio Vargas (1978), mestrado em Economia aplicada à Administração pela mesma escola (1982) e doutorado em Ciência Econômica pela Universidade Estadual de Campinas (1992). Realizou estudos de pós-doutorado na Universidade de Londres e na Universidade da Califórnia em Berkeley. Livre Docente em Economia pela Unicamp (1999). Foi membro do CONSEA - Conselho Nacional de Segurança Alimentar e Nutricional (2003-07). Foi também Coordenador da Iniciativa 
América Latina e Caribe sem Fome, projeto conduzido pela FAO / ONU, durante o ano de 2007. Foi Coordenador do NEPA - Núcleo de Estudos e Pesquisas em Alimentação da Unicamp por dois mandatos, entre 2008 e 2012. Atuou como Diretor do Instituto Confúcio da Unicamp entre 2014 e 2016. Pesquisador na área de Economia, com ênfase em Economias Agrária e dos Recursos Naturais, atuando principalmente nos seguintes temas: agroindústria e distribuição de alimentos, segurança alimentar, organização dos grupos de interesse na agricultura, geração de renda no meio rural e políticas sociais. Bolsista Produtividade em Pesquisa CNPq PQ-2.wbelik@hotmail.com

Como citar: PENHA, Thales Augusto Medeiros; BELIK, Walter. O impacto das certificações nas cadeias globais de valor agrícolas: o caso das frutas frescas no Nordeste brasileiro. Redes, Santa Cruz do Sul, v. 24, n. 1, p. 187-211, jan. 2019. ISSN 1982-6745. Disponível em: https://doi.org/10.17058/redes.v24i1.12861. 